\title{
Child Labour and Inequality
}

\author{
Simone D'Alessandro* Tamara Fioroni ${ }^{\dagger}$
}

\begin{abstract}
This paper focuses on the role that inequality plays in shaping political support for child labour regulation policies. We provide a model on the evolution of child labour, fertility and human capital where the heterogeneity between low- and high-skilled workers allows for an endogenous analysis of inequality generated by child labour. Depending on the initial level of inequality, child labour regulation policies can affect the welfare of low- and high-skilled workers in different ways and therefore can have an impact on political support for their introduction. The possible conflicts of interest that may arise between the two groups can help explain the difficulties that many governments have when dealing with the issue of child labour.
\end{abstract}

JEL classification: J13; J24; I24; O40.

Keywords: Child Labour, Fertility, Human capital, Inequality, Child labour regulation.

*Dipartimento di Economia, Università di Pisa, Via Ridolfi 10, Pisa, Italy. Tel.: +39 050 2216333; Fax: +39050 598040. E-mail address: s.dale@ec.unipi.it.

†Dipartmento di Scienze Economiche, Università degli Studi di Verona, Vicolo Campofiore, 2 - 37129 Verona, Italy. E-mail address: tamara.fioroni@univr.it. 


\section{Introduction}

Ever since the latter half of the 19th century the regulation of child labour has sparked many a heated political debate. De Herdt (1996), for example, when writing about nineteenth century Belgium observes that, although it was one of the most industrialized countries in Western Europe, it was also the last one to introduce a law on child labour mainly due to strong opposition from the industrialists. In particular he points out: "In his speech of 8 November 1842 King Leopold announced a bill for the protection of children working in the manufacturing industry....This led in 1848 to the introduction of a rather progressive bill which, had it been passed, would have prohibited child labour under the age of 10...Industrialists however were the dominant force in Belgian politics, and they successfully argued that the bill's restriction on their economic freedom would make Belgian industry uncompetitive, it did not become law". On the other hand, Cunningham (1996) observes that the greatest opposition to the introduction of child labour laws in Lancashire found its loudest voice amongst the working class. Similarly, Nardinelli (1990) regarding the United States, notes that it was the mill workers of the South, particularly those with numerous children, who were the major opponents to child labour restrictions due to the resulting potential loss of income. Moreover, Kleinberg (2005) shows that the political campaigning for the introduction of compulsory education was mostly supported by the middle class whereas the principal opposition came from the working class.

Political debate and the economic forces at work in the 19th century in now developed countries continue to be seen in many developing countries today. However, the main difference is that modern-day developing countries may be forced, through international political pressure, to adopt child labor regulation even against the will of its citizenry (Krueger and Donohue, 2005). Notwithstanding external political constraints, child labour remains all too diffuse in many developing countries where regulation policies are either weak or barely enforced (Doepke and Zilibotti, 2005). According to the International Labour Organization (2013), in 2012, approximately 168 
million children between the ages of 5 to 17 were at work (this accounts for almost 11 per cent of all children in this age group across the world), with the highest incidence existing in Sub-Saharan Africa (21\% compared with 9\% in Asia, the Pacific, Latin America and the Caribbean, and with $8 \%$ in the Middle East and North Africa)(Edmonds, 2008).

Regarding India of the 1990s, Weiner (1991) points out: "India has made less of an effort to move children out of the labor force and out of their homes into the school system than many other countries not for economic or demographic reasons but because of the attitudes of government officials, politicians, trade union leaders, workers in voluntary agencies, religious figures, intellectuals, and the influential middle class toward child labor and compulsory primary school education." (Weiner, 1991 p.12). He, therefore, argues that poverty is not the sole contributor to the persistence of child labour. In particular, he observes that many African countries, with income levels lower than those of India, have expanded mass education with impressive increases in literacy. In line with this view, Cigno and Rosati (2005, p.4) argue that although income and child labour are negatively correlated, this correlation, however, is not strong and assert that "countries with similar per capita income can have very different levels of child labour, especially at low levels of income, and even relatively prosperous countries present a high incidence of child labour." (see also e.g. Dessy and Vencatachellum, 2003).

In this paper we develop a theoretical model to enable us to analyze the dynamics behind low political support and possible conflicts of interest regarding child labor regulations. In particular, we study the relationship between inequality, welfare and child labour regulation policies. We expand on the existing literature regarding child labour and endogenous fertility to take into account two groups of individuals with two different levels of human capital. $^{1}$ In this respect, our framework is closely related to the literature

\footnotetext{
${ }^{1}$ See Basu and Van, 1998; Basu, 1999, 2000; Baland and Robinson, 2000; Dessy and Pallage, 2001, 2005; Ranjan, 1999, 2001 for an analysis of child labour with exogenous fertility. See Dessy (2000), Hazan and Berdugo (2002) and Doepke and Zilibotti (2005) for an analysis of child labour with endogenous fertility.
} 
on inequality, differential fertility and economic growth. De la Croix and Doepke (2003, 2004), and Moav (2005) show that the differential fertility between rich and poor can offer an explanation to the persistence of poverty within and across countries - a phenomenon called "dynastic trap" by Basu and Tzannatos (2003). Although, we use a similar overlapping generations framework, we concentrate on the policies aimed to reduce child labour in an economy with an unequal distribution of income.

A number of theoretical studies focus on the political support for child labour regulation (CLR) policies. The conventional wisdom is that the opposition to CLR stems from poor households, since child labour represents an important source of income and moreover, the long delay between the costs and the returns of investing in education is unattractive. However, in a general equilibrium setup, where child labour is a substitute for adult labour, policies that restrict child labour bring about a reduction in the labour supply. This effect leads to a wage increase which may offset the negative income effect of child labour contraction. Based on this trade-off, Krueger and Donohue (2005), Doepke and Zilibotti (2005), Doepke and Krueger (2006) and Dessy and Knowles (2008) develop dynamic general equilibrium models to clarify the distributional effects of policies aiming to contrast child labour and the identification of groups which may support CLR policies. The key novelty of our paper with respect to this literature is to highlight the role that inequality plays in shaping the political support of low- and high-skilled workers for CLR policies. In fact, we show that depending on the initial level of inequality CLR policies affect the welfare of low- and high-skilled workers in different ways.

In particular, in the short run, along the transition path, if inequality is low - that is high-skilled parents do not choose the maximum level of education - CLR policies reduce the welfare of the high-skilled and can increase the welfare of the low-skilled. Indeed, if the reliance of low-skilled parents' income on child labour is insufficiently high, then the positive effect of CLR on unskilled wages exceeds the loss in family income. 
By contrast, if inequality is high - that is high-skilled parents choose the maximum level of education - CLR policies always reduce the welfare of the unskilled group and leave the welfare of high-skilled households unchanged. In the steady state, where wages are constant, CLR affects only the income generated by children. Thus, when inequality is low the welfare of both skilled and unskilled parents decreases due to the loss of child labour income. On the other hand, when inequality is high only the welfare of unskilled parents decreases.

Finally, in the long run, CLR policies slow the transition path to the steady state, and increase the level of income of the unskilled dynasties whilst reducing that of the high-skilled. If the policy is implemented once the economy is in the steady state, the level of human capital of the high-skilled may decrease since the earning coming from child labour increases relatively to that of high-skilled labour.

The paper is organized as follows. Section 2 describes the basic structure of the model. Section 3 presents the properties of the short-run general equilibrium. Section 4 shows the long-run dynamics of the economy. Section 5 derives the implications of CLR policies and Section 6 concludes.

\section{The Model}

We analyse an overlapping-generations economy which is populated by $N_{t}$ individuals. Each of them is endowed with a level of human capital, $h_{t}^{i}$. This level is endogenously determined by parents' choice concerning their children's time allocation between labour and schooling. Adults can supply skilled or unskilled labour, while children can only supply unskilled labour. This setup is consistent with much of the literature on income distribution and development (see, for instance, Galor and Zeira, 1993), and was also recently introduced in the issue of child labour and economic growth (i.e. Hazan and Berdugo, 2002). 


\subsection{Production}

We assume that labour is the only production factor. According to Doepke and Zilibotti (2005), production occurs according to a constant-returns-toscale technology using unskilled and skilled labour as inputs. We define $H_{t}$ the total number of efficiency units of skilled labour and $L_{t}$ the number of unskilled workers. Since the aim of the paper is to investigate the relations between child labour, unskilled and skilled labour, for the sake of argument, we abstract from capital in the production function. Thus the output produced at time $t$ is

$$
Y_{t}=\psi\left(H_{t}\right)^{\mu}\left(L_{t}\right)^{1-\mu}=\psi\left(s_{t}\right)^{\mu} L_{t}
$$

where $s_{t} \equiv H_{t} / L_{t}$ is the ratio of skilled to unskilled labour employed in production in period $t, \psi>0$ and $0<\mu<1$. $^{2}$ In every period $t$, firms choose the level of unskilled labour, $L_{t}$, and the efficiency units of labour, $H_{t}$, so as to maximise profits. Thus the wage of unskilled workers, i.e. $w_{t}^{u}$, and the wage rate per efficiency unit, $w_{t}^{s}$, are

$$
w_{t}^{u}=\psi(1-\mu)\left(s_{t}\right)^{\mu},
$$

and

$$
w_{t}^{s}=\psi \mu\left(s_{t}\right)^{\mu-1}
$$

Since each adult $i$ is endowed with a certain level of human capital $h_{t}^{i}$, he/she chooses to work as unskilled if, and only if, $w_{t}^{s} h_{t}^{i}<w_{t}^{u}$, while he/she works as skilled if, and only if, $w_{t}^{s} h_{t}^{i}>w_{t}^{u}$. If, for instance, the level of human capital were uniformly distributed in the population, given the level of wages $w^{s}$ and $w^{u}$, there would be an adult $i^{*}$ such that $w_{t}^{s} h_{t}^{i^{*}}=w_{t}^{u}$. All the adults with a level of human capital $h^{i}<h^{i^{*}}$ would choose to work as unskilled,

\footnotetext{
${ }^{2}$ As an alternative interpretation, we are assuming that labour contributes to production through two distinct services, physical effort ("brawn") and mental effort ("brain"). Unskilled labour and children provide physical effort, while skilled labour provides mental effort. For instance, this argument can be found in Stokey (1996).
} 
while the adults with a level $h^{i}>h^{i^{*}}$ would choose to work as skilled. In terms of income, agents with $h^{i}>h^{i^{*}}$ obtain a wage proportional to their level of human capital, while agents with $h^{i}<h^{i^{*}}$ obtain the same wage, $w^{u}$, irrespective of their level of human capital. ${ }^{3}$

\section{$2.2 \quad$ Preferences}

Members of generation $t$ live for two periods: childhood and adulthood. In childhood, individuals may either work, go to school or both. In adulthood, agents supply unskilled or skilled labour. Individuals' preferences are defined over consumption, i.e. $c_{t}^{i}$, the number of children $n_{t}^{i}$, and the human capital of children $h_{t+1}^{i}$. The utility function of an agent $i$ of generation $t$ is given by

$$
U_{t}^{i}=\alpha \ln c_{t}^{i}+(1-\alpha) \ln \left(n_{t}^{i} h_{t+1}^{i}\right)
$$

where $\alpha \in(0,1)$ is the altruism factor. As it is clear from equation (4), we assume that parents are aware of the human capital of their children rather than their income. This is typical of the "warm-glow" approach: parents get direct satisfaction from investing in the education of their children - by satisfying their sense of duty as good parents - regardless of the impact on the wages of their children in adulthood (see for instance Banerjee, 2004, Strulik, 2004 and Das et al., 2015). Balothra (2004) also finds empirical support of parental altruism.

Human capital of children in period $t+1$ is an increasing, strictly concave function of the time devoted to school, that is

$$
h_{t+1}^{i}=a\left(b+e_{t}^{i}\right)^{\beta},
$$

where $a, b>0$ and $\beta \in(0,1)$. The fact that $b>0$ means that every adult is endowed with a positive level of human capital even if parents did not invest

\footnotetext{
${ }^{3}$ This feature can partly take into account the education-occupation mismatches. In our model this mismatch is endogenously determined by the level of wages in the two labour markets and does not result in income penalties.
} 
in their education in childhood (see e.g. Galor and Tsiddon, 1997, Galor and Weil, 2000 and De la Croix and Doepke, 2004).

Parents allocate their income between consumption and child rearing. In particular, raising each born child takes a fraction $z \in(0,1)$ of an adult's income. Parents choose the allocation of children's time between schooling, $e_{t}^{i} \in[0,1]$, and labour force participation $\left(1-e_{t}^{i}\right) \in[0,1]$.

Each child can offer only $\theta \in[0, z)$ units of unskilled labour. $\theta<1$ implies that children are relatively less productive than unskilled adult workers and $\theta<z$ implies that the cost of having children is positive even if parents choose to always send them to work. School is free, there is not a direct cost associated with schooling (Azariadis and Drazen, 1990), thus the only cost of education is the opportunity cost of not working as a child.

As we pointed out above, while children can only work as unskilled workers, parents will choose to work in the sector that guarantees them the highest income. Thus, each household has two potential sources of income: i) parent income, $I_{t}^{i}=\max \left\{w_{t}^{s} h_{t}^{i}, w_{t}^{u}\right\}$ and, ii) child income, $\left(1-e_{t}^{i}\right) \theta w_{t}^{u}$.

The budget constraint is therefore

$$
c_{t}^{i} \leq\left(1-z n_{t}^{i}\right) I_{t}^{i}+\left(1-e_{t}^{i}\right) \theta w_{t}^{u} n_{t}^{i}
$$

\subsection{Individual choices}

Each household chooses $c_{t}^{i}, n_{t}^{i}$ and $e_{t}^{i}$ so as to maximize the utility function (4) subject to the budget constraint (6). Given $I_{t}^{i}$, the optimal consumption, the optimal schooling and the optimal number of children chosen by member $i$ are

$$
\begin{gathered}
c_{t}=\alpha I_{t}^{i} ; \\
e_{t}^{i}= \begin{cases}0 & \text { if } r_{t}^{i} \leq \frac{\theta(\beta+b)}{\beta z}, \\
\frac{r_{t}^{i} \beta z-\theta(\beta+b)}{\theta(1-\beta)} & \text { if } \frac{\theta(\beta+b)}{\beta z} \leq r_{t}^{i} \leq \frac{\theta(1+b)}{\beta z}, \\
1 & \text { if } r_{t}^{i} \geq \frac{\theta(1+b)}{\beta z} ;\end{cases}
\end{gathered}
$$


and

$$
n_{t}^{i}= \begin{cases}\frac{(1-\alpha) r_{t}^{i}}{z r_{t}^{i}-\theta} & \text { if } r_{t}^{i} \leq \frac{\theta(\beta+b)}{\beta z}, \\ \frac{(1-\alpha)(1-\beta) r_{t}^{i}}{z r_{t}^{i}-\theta(1+b)} & \text { if } \frac{\theta(\beta+b)}{\beta z} \leq r_{t}^{i} \leq \frac{\theta(1+b)}{\beta z}, \\ \frac{1-\alpha}{z} & \text { if } r_{t}^{i} \geq \frac{\theta(1+b)}{\beta z}\end{cases}
$$

where $r_{t}^{i} \equiv I_{t}^{i} / w_{t}^{u}$ is the earnings ratio between skilled and unskilled labour which is

$$
r_{t}^{i}= \begin{cases}1 & \text { if } w_{t}^{s} h_{t}^{i} \leq w_{t}^{u}, \\ \frac{w_{t}^{s} h_{t}^{i}}{w_{t}^{u}} & \text { if } w_{t}^{s} h_{t}^{i}>w_{t}^{u} .\end{cases}
$$

It is important to highlight that, if child labour were absent, parents, irrespective of their level of income, would choose the maximum level of education and the minimum level of fertility, i.e. $(1-\alpha) / z$. The presence of child labour, however, lowers the cost of children and therefore leads to a higher fertility rate and different fertility and educational choices between skilled and unskilled parents.

When parents supply skilled labour, i.e. $h^{i}>h^{i^{*}}$, educational and fertility choices depend on the earnings ratio, $r_{t}^{i}{ }^{4}$ In particular, when the earnings ratio increases, the optimal number of children declines and the time allocated to children's schooling increases because the relative importance of children's earnings goes down. Thus, according to the existing literature, the model shows a trade-off between quantity and quality of children, but this trade-off is due to the presence of child labour.

On the other hand, when parents supply unskilled labour, $r_{t}^{i}=1$, their choices regarding fertility and education only depend on the relative cost of child-raising, i.e. $z / \theta$ - see equations (8) and (9). Hence, every adult endowed with a level of human capital $h^{i}<h^{i^{*}}$ makes the same fertility and

\footnotetext{
${ }^{4}$ If we introduce a direct cost of schooling, the threshold level of parental income below which parents send their children to work will rise, and hence the incidence of child labour will increase. Although such an assumption may be more realistic, its introduction would mean including a sector for education because our aim is to endogenously determine the level of wages in a general equilibrium framework.
} 
schooling decisions. Consequently, their children will be endowed with the same level of human capital regardless of the parent's level of human capital. This feature is due to the substitutability between child labour and unskilled labour. Furthermore, an increase (a reduction) in the unskilled wage does not affect fertility and schooling decisions but it increases (reduces) consumption and therefore household's utility.

\section{General Equilibrium: Short Run}

The last result highlights the emergence of a marked asymmetry between agents supplying skilled or unskilled labour. For the sake of argument, we assume that in the initial period, $t$, the population is composed of two groups which are endowed with two different levels of human capital. There are $N_{t}^{u}$ low-skilled workers endowed with a level of human capital $h_{t}^{u}$, and $N_{t}^{s}$ highskilled workers endowed with a level of human capital $h_{t}^{s}$. We show that differences in human capital will persist and increase across generations and that the consequent divergence in fertility decisions will change the size of the two groups. Furthermore, due to general equilibrium effects during the transition inequality increases.

As we pointed out above, an important feature of this framework is that, if $w_{t}^{s} h_{t}^{u}<w_{t}^{u}$, low-skilled workers choose to work as unskilled, while if $w_{t}^{s} h_{t}^{u}>$ $w_{t}^{u}$ they would prefer to work as skilled. Thus, given perfect mobility of labour, at equilibrium $w_{t}^{s} h_{t}^{u} \leq w_{t}^{u}$ must hold; otherwise all the adult labour force would offer skilled labour. A similar argument applies to high-skilled workers; thus $w_{t}^{s} h_{t}^{s} \geq w_{t}^{u}$. Therefore, for any $h_{t}^{u} \leq h_{t}^{s}$, at equilibrium

$$
h_{t}^{u} \leq \frac{w_{t}^{u}}{w_{t}^{s}} \leq h_{t}^{s}
$$

From equations (10) and (11), it holds that

$$
r_{t}^{u}=1
$$


and

$$
1 \leq r_{t}^{s} \leq \frac{h_{t}^{s}}{h_{t}^{u}}
$$

for all $t \in \mathbb{N}_{0}$. Thus choices of education and fertility of the two groups can be obtained substituting $r_{t}^{u}=1$ and $r_{t}^{s}$ in equations (8) and (9) respectively.

Inequality (11) points out that three distinct regimes arise in this framework:

1. $h_{t}^{u}<\frac{w_{t}^{u}}{w_{t}^{s}}<h_{t}^{s}$, i.e. low-skilled agents only supply unskilled labour and high-skilled agents only supply skilled labour;

2. $w_{t}^{s} h_{t}^{u}=w_{t}^{u}$, i.e. a fraction of low-skilled workers work as skilled;

3. $w_{t}^{s} h_{t}^{s}=w_{t}^{u}$, i.e. high-skilled workers are indifferent about to doing skilled or unskilled work.

Note that if, in period $t$, market equilibrium implies $w_{t}^{s} h_{t}^{s}=w_{t}^{u}$, thus in period $t+1$ there will be no difference between low- and high-skilled workers, since low- and high-skilled workers have the same adult income and make the same schooling and fertility decisions. This argument does not apply when $w_{t}^{s} h_{t}^{u}=w_{t}^{u}$, since in this case high-skilled workers get a higher income equal to $w_{t}^{s} h_{t}^{s}$ greater than $w_{t}^{u}$ since $h_{t}^{s}>h_{t}^{u}$.

\subsection{Interior regime}

Let us assume that in period $t, h_{t}^{u}<\frac{w_{t}^{u}}{w_{t}^{s}}<h_{t}^{s}$, i.e. $1<r_{t}^{s}<\frac{h_{t}^{s}}{h_{t}^{u}}$. In this regime, at equilibrium - if it exists - the economy is characterized by two income groups $\left(w_{t}^{s} h_{t}^{s}>w_{t}^{u}\right)$, which make different fertility and schooling decisions see equations (8) and (9).

Thus the aggregate demand is

$$
D_{t}=c_{t}^{u} N_{t}^{u}+c_{t}^{s} N_{t}^{s}
$$

where $N_{t}^{u}$ and $N_{t}^{s}$ are, respectively, the number of low- and high-skilled agents, and from equations (2), (3) and (7),

$$
\begin{aligned}
c_{t}^{u} & =\alpha \psi(1-\mu) s_{t}^{\mu}, \\
c_{t}^{s} & =\alpha h_{t}^{s} \psi \mu s_{t}^{\mu-1} .
\end{aligned}
$$


At time $t$, the supply of unskilled labour is given by the labour supplied by low-skilled adults, i.e. $\left(1-z n_{t}^{u}\right) N_{t}^{u}$, plus the labour supplied by the children of low- and high-skilled parents, i.e. $\left(1-e_{t}^{u}\right) n_{t}^{u} N_{t}^{u}$ and $\left(1-e_{t}^{s}\right) n_{t}^{s} N_{t}^{s}$. At equilibrium this supply must be equal to the total demand of unskilled labour, $L_{t}$, that is,

$$
L_{t}=\left(1-z n_{t}^{u}\right) N_{t}^{u}+\theta\left[\left(1-e_{t}^{u}\right) n_{t}^{u} N_{t}^{u}+\left(1-e_{t}^{s}\right) n_{t}^{s} N_{t}^{s}\right]
$$

Moreover, the supply of skilled labour must be equal to the demand for skilled labour $H_{t}$, that is

$$
H_{t}=\left(1-z n_{t}^{s}\right) h_{t}^{s} N_{t}^{s}
$$

From equations (1), (14), (15) and (16), the equilibrium in the goods market yields

$$
L_{t}=\alpha \frac{(1-\mu) s_{t} N_{t}^{u}+\mu h^{s} N_{t}^{s}}{s_{t}}
$$

The ratio between equations (18) and (19) defines the equilibrium level of $s_{t}$

$$
s_{t}^{*}=\frac{h_{t}^{s}}{1-\mu}\left[\frac{1-z n_{t}^{s}}{\alpha}-\mu\right] \frac{1}{x_{t}},
$$

where $x_{t} \equiv N_{t}^{u} / N_{t}^{s}$. Note that in period $t, s_{t}^{*}$ depends only on the choice of $n_{t}^{s .5}$ The other variables $N_{t}^{s}, N_{t}^{u}$ and $h_{t}^{s}$ depend on choices made in period $t-1$.

In order to understand the relation between $s_{t}^{*}$ and $n_{t}^{s}$ it is convenient to rewrite $r_{t}^{s}$. From equations (2), (3) and (20), we obtain:

$$
r_{t}^{s}=\frac{w_{t}^{s} h_{t}^{s}}{w_{t}^{u}}=\frac{\mu \alpha x_{t}}{1-z n_{t}^{s}-\mu \alpha}
$$

${ }^{5}$ The fact that the ratio $s^{*}$ does not depend on education and fertility choices of unskilled workers is an implication of the trade-off between quantity and quality of offspring in the utility of the parents and of the perfect substitutability between child labour and unskilled labour (see Dessy, 2000). A higher (lower) labour supply of low-skilled parents, induced by a decline (increase) in fertility, exactly offsets the loss of labour supplied by their children. 
which depends only on $n_{t}^{s}$. This function takes different values according to the value of $r_{t}^{s}$. Thus, at equilibrium

$$
r_{t}^{s *}=\left\{\begin{array}{ccc}
\frac{2 \theta \alpha \mu x_{t}}{\theta(1-\alpha \mu)+z \alpha \mu x_{t}-\sqrt{\Delta_{1}\left(x_{t}\right)}} & \text { if } & x_{t} \leq x_{2} \\
\frac{2 \theta(1+b) \alpha \mu x_{t}}{\theta(1+b)(1-\alpha \mu)+z \alpha \mu x_{t}-\sqrt{\Delta_{2}\left(x_{t}\right)}} & \text { if } & x_{2} \leq x_{t} \leq x_{3} \\
\frac{\mu}{1-\mu} x_{t} & \text { if } & x_{3} \leq x_{t}
\end{array}\right.
$$

where $\Delta_{1}\left(x_{t}\right)=\left[z \alpha \mu x_{t}-\theta(1-\alpha \mu)\right]^{2}+4 \theta(1-\alpha) z \alpha \mu x_{t}$ and $\Delta_{2}\left(x_{t}\right)=\left[z \alpha \mu x_{t}-\right.$ $\theta(1+b)(1-\alpha \mu)]^{2}+4 \theta(1+b)(1-\beta)(1-\alpha) z \alpha \mu x_{t} ; x_{2}=\frac{\theta(b+\beta)[b \alpha(1-\mu)-\beta(1-\alpha)]}{z \alpha \mu \beta b}$, $x_{3}=\frac{\theta(1-\mu)(1+b)}{\mu \beta z}$.

Given $r_{t}^{s *}$, it is easy to get the equilibrium values for all the other variables in particular $n_{t}^{s *}, e_{t}^{s *}$. The equilibrium value of $r_{t}^{s *}$ depends only on the ratio between the number of low- and high-skilled workers, i.e. $x_{t}$. In particular, for $x_{t} \leq x_{2}$ high- (and low-) skilled workers do not invest in education $\left(e_{t}^{s}=0\right)$, for $x_{2}<x_{t}<x_{3}$ high-skilled workers send their children to work and to school $\left(0<e_{t}^{s}<1\right)$, and for $x_{3} \leq x_{t}$ high-skilled workers only send their children to school $\left(e_{t}^{s}=1\right)$.

Moreover, in an interior equilibrium it must hold that $1<r_{t}^{s *}<\frac{h_{t}^{s}}{h_{t}^{u}}$. Thus for some values of $x_{t}$ there may be no interior solution. Figure 1 clarifies this result. The function $r_{t}^{s *}$ is a piecewise function defined in the interval $\underline{x} \leq x_{t} \leq \bar{x}$ - that implies $1<r_{t}^{s *}<\frac{h_{t}^{s}}{h_{t}^{u}}-$ where an interior equilibrium always exists ${ }^{6}$.

In the case presented in Figure 1, as long as $x_{t}$ increases $r_{t}^{s *}$ becomes equal to $\frac{h_{t}^{s}}{h_{t}^{u}}$ before reaching the level $\frac{\theta(1+b)}{\beta z}$, that is the level which ensures $e_{t}^{s}=1$. In Appendix A we show that the derivative of $r_{t}^{s *}$ with respect of $x_{t}$ is always positive.

\footnotetext{
${ }^{6}$ The boundaries $\underline{x}$ and $\bar{x}$ can cross the function $r_{t}^{s *}$ in each of the three intervals depending on the values of the parameters. Thus many different cases may arise, but such an analysis does not give much insight.
} 


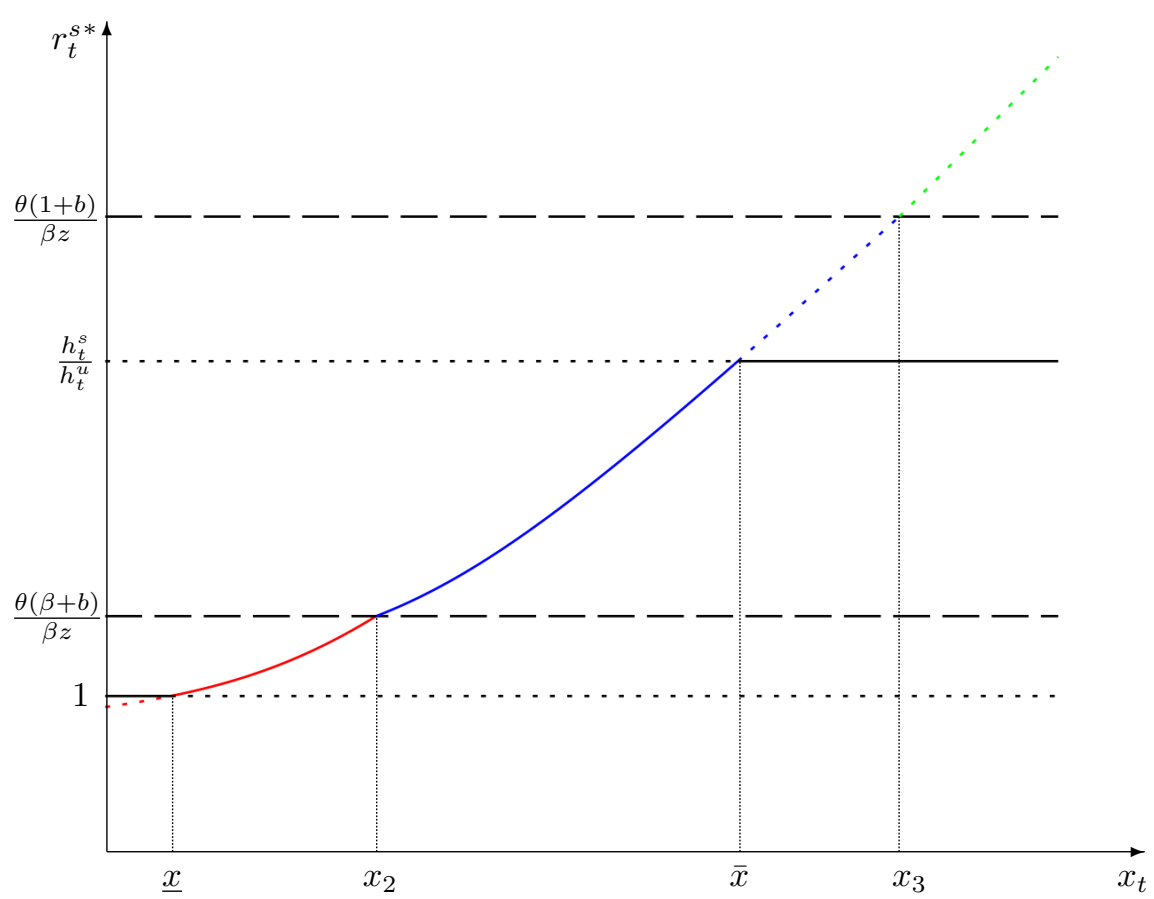

Figure 1: A numerical illustration of $r_{t}^{s *}$ as a function of $x_{t}$. An interior equilibrium exists if, and only if, $\underline{x} \leq x_{t} \leq \bar{x}$. Value of parameters: $\alpha=0.9 ; \mu=0.3 ; z=0.3 ; \theta=0.25$; $\beta=0.4 ; b=0.2 ; a=1$.

\subsection{Corner regimes}

For $0 \leq x_{t} \leq \underline{x}$, the number of high-skilled workers is so large, given the available technology, that the wage of the high-skilled equals the wage of the unskilled $\left(w_{t}^{s} h_{t}^{s}=w_{t}^{u}\right)$. This means that $r_{t}^{u}=r_{t}^{s *}=1$ (see Figure 1).

On the other hand, for $x_{t} \geq \bar{x}$, there are so few high-skilled workers with respect to low-skilled, given the available technology, that the efficiency wage $\left(w_{t}^{s}\right)$ is high enough to allow the low-skilled to work as skilled, while getting the same wage as unskilled workers, i.e. $w_{t}^{s} h_{t}^{u}=w_{t}^{u}$. Thus $r_{t}^{s *}=\frac{h_{t}^{s}}{h_{t}^{u}}$.

From equations (2) and (3), the condition $w_{t}^{s} h_{t}^{u}=w_{t}^{u}$ implies that

$$
s_{t}=\frac{\mu h_{t}^{u}}{1-\mu} .
$$

In Appendix B we show that in any period, it is possible to determine the equilibrium fraction of low-skilled workers that work as skilled or as unskilled.

To summarize the above analysis of three regimes allows us to have a 
complete characterization of the short run equilibrium. The ratio between the number of low- and high-skilled workers $x_{t}$ and the ratio $h_{t}^{s} / h_{t}^{u}$ establish the appropriate regime.

\section{Long-Run Dynamics}

Fertility choices of the high and low-skilled groups affect their relative size in the following period by shaping the new short-run equilibrium. Thus in the long run, the fertility differential is crucial in determining the dynamics of the earnings ratio, and hence the dynamics of human capital.

Since $N_{t+1}^{u}=n_{t}^{u} N_{t}^{u}$ and $N_{t+1}^{s}=n_{t}^{s} N_{t}^{s}$, the population dynamics is given by

$$
N_{t+1}=n_{t}^{u} N_{t}^{u}+n_{t}^{s} N_{t}^{s}
$$

Thus the dynamics of $x_{t} \equiv N_{t}^{u} / N_{t}^{s}$ is given by

$$
x_{t+1}=\frac{n_{t}^{u}}{n_{t}^{s *}} x_{t}
$$

Note that since both $n_{t}^{u}$ and $n_{t}^{s *}$ are decreasing functions of income then $n_{t}^{u} \geq n_{t}^{s *}$.

The steady state may be defined as a trajectory in which individual choices do not change over time. Since choices at any period $t$ are affected by income, in a steady state the earnings ratio must be constant, which means that there must be a constant proportion of skilled and unskilled labour. However, as long as there is inequality in the economy (the income of the high-skilled is higher than the income of the low-skilled), the fertility choices between the two groups are different and the ratio $x_{t}$ changes over time. This implies that any short-run interior equilibrium cannot be a steady state.

There are three limiting cases, where inequality disappears after the first period - see equations (8), (9), (12) and (22).

First, if $\frac{z}{\theta} \geq \frac{(1+b)}{\beta}$, the relative cost of child-raising is so high that lowskilled workers choose the minimum family size and only send their children to school. The fertility choices of high and low-skilled workers are the same 
and the whole population will be characterized by the maximum level of human capital.

Second, if $\frac{z}{\theta} \leq \frac{(\beta+b)}{\beta}$ and $x_{t} \leq x_{2}$, both low and high-skilled workers send their children to work, since the relative cost of child-raising is low with respect to the return of human capital. Thus, the next generation will have the minimum level of human capital: the differences between the two classes disappear.

Third, if in period $t, x_{t} \leq \underline{x}$, then $r_{t}^{u}=r_{t}^{s}=1$ and therefore high- and low-skilled workers make the same choice of fertility and education.

Besides the above cases, the economy follows a transition with increasing inequality. For any $\max \left\{\underline{x}, x_{2}\right\}<x_{t}<\bar{x}$, the fertility of high-skilled workers is permanently lower than the fertility of low-skilled workers. Thus, from equation (25), during the transition $x_{t}$ increases over time. This change directly affects the earnings ratio since the supply of unskilled labour increases more than the supply of skilled labour. The increase in $x_{t}$ induces an increase in $r_{t}^{s *}$ (see Figure 1), which in turns brings about a rise in the human capital of children of high-skilled parents, i.e. $h_{t+1}^{s}$. Both those consequences favour the group of high-skilled workers, since the dynasty experiences an increase in skilled wage and an increase in the level of human capital.

This process generates a continuous expansion in inequality and child labour, because generation by generation the number of high-skilled workers decreases and becomes richer whereas the number of low-skilled workers increases and they become poorer.

The increase in $h_{t}^{s}$ leads to an increase in $\bar{x}$ (see Figure 1), which may allow the dynamics of human capital to reach its maximum level. However, since the accumulation of human capital is bound, the continuous increase in $x_{t}$ implies that in a certain time period, for instance $t=\tilde{t}$, the population ratio $x_{t}$ reaches the threshold level $\bar{x}$ at which point the wage ratio becomes constant, i.e. $w_{t}^{u} / w_{t}^{s}=h_{t}^{u}$. This implies that in the time interval $t>\tilde{t}$ the low-skilled are indifferent to working as either skilled or unskilled workers and the proportion of the skilled and the unskilled will be constant to maintain 
wages constant. We summarize the above results in the following proposition.

Proposition 4.1. The economy admits only one steady state with inequality. This equilibrium will be reached at a certain period $t$ if, and only if, at the initial period $t=0$

$$
\begin{aligned}
& \text { i. } \frac{(\beta+b)}{\beta}<\frac{z}{\theta}<\frac{(1+b)}{\beta} \text { and } x_{0}>\underline{x} ; \text { or } \\
& \text { ii. } \frac{(\beta+b)}{\beta} \geq \frac{z}{\theta} \text { and } x_{0}>\max \left\{\underline{x}, x_{2}\right\} .
\end{aligned}
$$

Furthermore, such a steady state is characterized by the condition $w_{\tau}^{s} h_{\tau}^{u}=w_{\tau}^{u}$ $\forall \tau \geq t$.

The fact that the steady state with inequality implies that $w_{t}^{s} h_{t}^{u}=w_{t}^{u}$, does not mean that the inverse implication is true. Let us assume that in period $t=\tilde{t}$ the population ratio $x_{\tilde{t}}$ reaches the threshold level $\bar{x}$. Since in period $\tilde{t}-1, w_{\tilde{t}-1}^{s} h_{\tilde{t}-1}^{u}<w_{\tilde{t}-1}^{u}$, in period $t=\tilde{t}$ high-skilled workers receive an income higher than in period $\tilde{t}-1$. Hence, if high-skilled workers have already chosen $e_{\tilde{t}-1}^{s}=1$ their choices of fertility and education do not change in period $\tilde{t}$ and the equilibrium is instantaneously reached. On the contrary, if $e_{\tilde{t}-1}^{s}<1$, their choices of education in period $\tilde{t}$ will increase. However, when $w_{t}^{s} h_{t}^{u}=w_{t}^{u}$, earnings are constant and therefore the dynamic of $r_{t+1}^{s}=\frac{h_{t+1}^{s}}{h_{t+1}^{u}}$ depends only on $r_{t}^{s}=\frac{h_{t}^{s}}{h_{t}^{u}} \cdot$

Figure 2 provides a graphical representation of the dynamics of $r_{t+1}^{s}$. Given the parameter values, the equilibrium choice can be obtained for $e^{u}=0$ or $e^{u}>0$, Figure 2(a) and 2(b) respectively. Once the economy has reached the condition $w_{t}^{s} h_{t}^{u}=w_{t}^{u}, r_{t+1}^{s}$ can follow one of the two curves in each case, converging to the respective equilibria $H^{L}$ and $H^{S}$ (see Appendix $\mathrm{C}$ for a detailed characterization of the two cases).

To summarize, during the transition path inequality rises since the fertility differential together with child labour generate an increase in the return of human capital which is only captured by high-skilled workers. Such

\footnotetext{
${ }^{7}$ We abstract from the case in which the increase in $h^{s}$ is such that the rise in the supply of skilled work is sufficient to cover the demand for skilled labour. Even in this particular situation, the dynamics of the system will tend to re-establish the condition $w_{t}^{s} h_{t}^{u}=w_{t}^{u}$ without altering the results.
} 


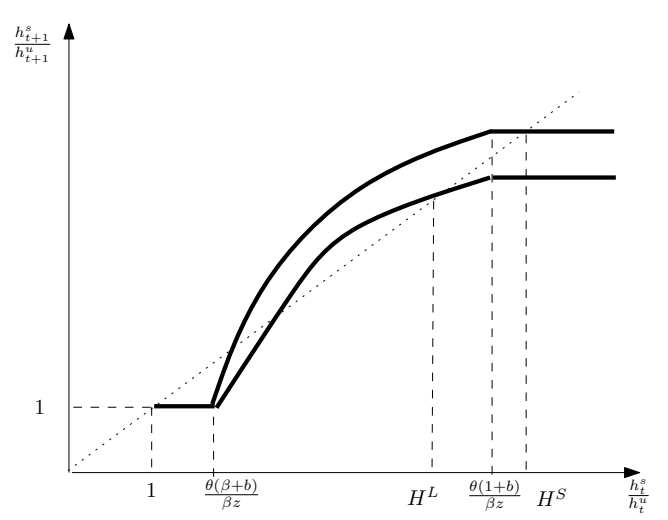

(a) Case $e^{u}=0$

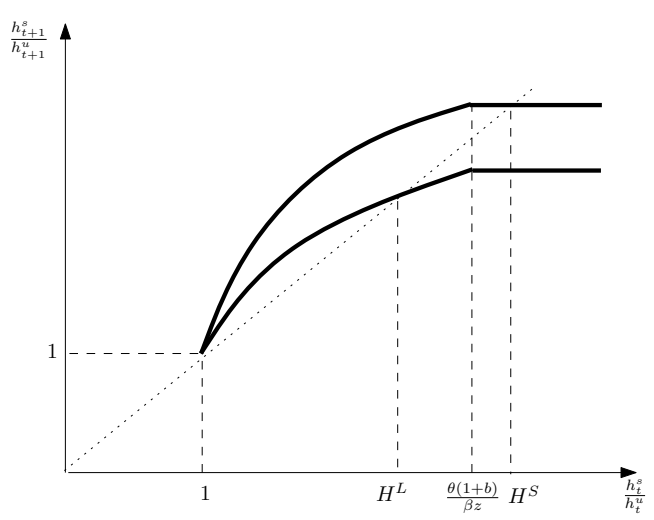

(b) Case $e^{u}>0$

Figure 2: The dynamic of $r_{t+1}^{s} \equiv \frac{h_{t+1}^{s}}{h_{t+1}^{u}}=f\left(r_{t}^{s}\right)$.

an increase leads the economy to converge to an equilibrium with inequality where low-skilled workers are indifferent to suppling either skilled or unskilled labour. In this steady state the earnings of the two groups are constant. However, the continuous increase in the relative size of low-skilled workers and the constant income of the two groups tend to reduce the Gini coefficient, and hence reduce the level of inequality in the economy. ${ }^{8}$ Finally, asymptotically the level of inequality tends to zero, since the fraction of income taken by the low-skilled group tends to 1 .

It is worth clarifying the interaction between child labour and inequality. The causality between the two variables is given by a dynamic interaction. Let us assume that the two groups are endowed with two different levels of human capital, that the economy produces the final consumption good by using both skilled and unskilled labour, and that there is a certain degree of child labour - i.e. $\frac{z}{\theta} \leq \frac{(1+b)}{\beta}$. If the economy is initially in the interior regime, the income of high-skilled workers is higher than the one of lowskilled workers. When low-skilled households send their children to work - for longer than high-skilled households - there is a fertility differential

\footnotetext{
${ }^{8}$ It is straightforward to compute the Gini coefficient when wages are constant i.e. $w^{u} / w^{s}=h^{u}$. The level of inequality increases when $x<\sqrt{h^{s} / h^{u}}$ and starts to decline when $x \geq \sqrt{h^{s} / h^{u}}$.
} 
between the two groups which leads the following generation to experience higher inequality. Thus child labour (or a child labour differential) induces a dynamic expansion of inequality during the transition. Poverty is not an issue in this dynamic interaction. If, for example, technology favoured unskilled labour, e.g. a decrease in $\mu$, fertility and schooling decisions would not be affected, without any impact on child labour in the short or in the long run. This property of the model allows us to analyze the impact of policies on the child labour/inequality nexus independently of the poverty issue.

\section{Child Labour Regulation Policies}

In our model the presence of free education is insufficient to either eradicate child labour or to reduce inequality. Indeed, as shown in the previous section, while for skilled parents the rise in the earnings ratio increases children's education across generations, low-skilled dynasties do not have any incentive to send their children to school.

The literature discusses a variety of policies aimed to reduce or eradicate child labour, e.g. ban on child labour, compulsory education, lump-sum increases in the household's full income, conditional cash transfer, rises in the marginal return to education. These policies may have different impacts on the utility of low- and high-skilled workers (see e.g. Doepke and Krueger, 2006 and Cigno and Rosati, 2005).

In this section we focus on a policy for child labour regulation (CLR) which imposes restrictions on the child labour market ${ }^{9}$. According to Doepke and Zilibotti (2005), such a policy can be equivalent to reducing the productivity of child labour - i.e. a decline in $\theta$. This impact is equivalent to a reduction in the opportunity cost of a child's time (Cigno and Rosati, 2005) . A full ban on child labour would mean $\theta=0$. In this particular case, given the assumption of free education, low- and high-skilled parents would only send their children since utility increases with the level of human capital of

\footnotetext{
${ }^{9}$ Section 5.3 provides a brief discussion on the effects of some other policies.
} 
children.

Not surprisingly, CLR policies, if applied, significantly shape the qualityquantity trade-off by inducing an increase in education and a reduction in fertility, and therefore lead to a lower level of inequality in the long run. However, as will become clearer, CLR is likely to run into political support issues. Indeed, the general equilibrium analysis provided in Section 3 allows us to investigate how a CLR policy, changing education and fertility choices, affects the earnings and therefore the level of utility of low- and high-skilled workers.

\subsection{CLR policies: short-run effects}

Since the results of CLR policies on welfare in the short run substantially differ according to whether the economy is in the transition or in the steady state, that is whether or not $w^{s} h^{u}=w^{u}$, we analyze the two cases separately.

Transition Path. It is worth differentiating the effects of a CLR policy where high-skilled workers partially send their children to work $-e^{s}<1-$ and where they only send their children to school $-e^{s}=1$ (for the sake of clarity, we drop the time index). We can interpret the first case as an economy with low inequality since the earnings ratio between skilled and unskilled labour is low. On the other hand, the second scenario can represent an economy with high inequality.

Consider first an economy with low inequality, i.e. $e^{s}<1$ and $0 \leq e^{u}<1$. A CLR policy tends to reduce the number of children of high-skilled adults and to increase their level of education. In Appendix $\mathrm{E}$ we show that the derivative of $n^{s *}$ with respect to $\theta$ is always positive. This change has an impact on the level of earnings at equilibrium. Indeed, from equation (20), a reduction in $n^{s *}$ implies an increase in $s^{*}$ which in turn leads to an increase in $w^{u}$ and a reduction in $w^{s}$ (see equations (2) and (3)).

A CLR policy has the same effect on low-skilled adults who reduce fertility and increase the level of education. However, their choices do not affect the 
equilibrium level of wages, since the reduction in child labour is exactly compensated by the increase in their labour supply because $z n^{u}$ decreases.

Proposition 5.1. When $e^{s}<1$ CLR policies induce a decline in the utility of high-skilled workers. Furthermore, there exists a level $\theta=\bar{\theta}>\frac{\beta z}{1+b}$ such that, for any $\theta<\bar{\theta}, C L R$ policies increase the level of utility for low-skilled workers.

Proof. Let us assume that $\theta$ decreases. Appendix E shows that in the shortrun general equilibrium both $w^{s}$ and $\theta w^{u}$ decrease since $n^{s}$ must decline. The effect of this change on the budget constraint of high-skilled parents is unambiguous. Indeed from equation (6) we have

$$
c^{s} \leq\left(1-z n^{s}\right) w^{s} h^{s}+\left(1-e^{s}\right) \theta w^{u} n^{s}
$$

Given the changes in $w^{s}$ and $\theta w^{u}$, the same basket of goods is no longer purchasable. Thus the attainable level of utility shifts down. ${ }^{10}$

For low-skilled parents the result is different. The budget constraint for the low-skilled is

$$
c^{u} \leq\left(1-z n^{u}\right) w^{u}+\left(1-e^{u}\right) \theta w^{u} n^{u} .
$$

Let us consider the right hand side. If low-skilled parents do not alter their choices, the first term increases (since $w^{u}$ increases), and the second decreases (since $\theta w^{u}$ decreases). However, as long as, $\theta$ tends to $\frac{\beta z}{1+b}$, from equation (8) $e^{u}$ tends to 1 and the second term tends to zero. Thus the negative effect of a decline in $\theta$ disappears.

Moreover, the maximum attainable level of utility of low-skilled parents is a $\mathrm{U}$-shaped function in $\theta$ with the minimum $\bar{\theta}$ that may also exceed $\frac{\beta z}{\beta+b}$. In such a case, the utility is always decreasing in $\theta$ in the relevant interval.

Thus for each $\theta<\bar{\theta}$ as $\theta$ decreases the level of parents' utility increases.

\footnotetext{
${ }^{10}$ It is probably more intuitive to consider an increase in $\theta$ since, in this case, both $w^{s}$ and $\theta w^{u}$ increase. If parents make the same education and fertility decisions, they can increase the level of consumption inducing an increase in their utility. The optimal choice will guarantee a level of utility higher than this hypothetical situation. For the same reason if $\theta$ decreases, the utility in the optimum is lower than in the initial situation.
} 
Proposition 5.2. When $e^{s}=1 C L R$ policies do not affect the welfare of high-skilled parents and bring about a decline in the level of utility of lowskilled workers.

Proof. In this case the choices of high-skilled parents do not depend on $\theta$. Thus the $s$ ratio does not change and wages are constant. Hence the level of utility of skilled parents is the same. On the contrary, the budget constraint for the low-skilled is

$$
c^{u} \leq\left(1-z n^{u}\right) w^{u}+\left(1-e^{u}\right) \theta w^{u} n^{u} .
$$

Since the only change in the budget constraint is the reduction in $\theta$, the cost of children increases, and as a consequence the same basket of goods is no longer purchasable. Thus, following the same argument as in Proposition 5.1 , the attainable level of utility of low-skilled parents decreases.

Steady state As we pointed out in Section 4, the steady state implies that $r^{s}=\frac{h^{s}}{h^{u}}$. In particular, since $s^{*}=\frac{\mu}{1-\mu} h^{u}$, whether $e^{s}=1$ or $e^{s}<1$, the wages in the economy do not change.

Nevertheless, the results are not the same in the two cases. Indeed, if a CLR policy is implemented and $e^{s}=1$, as mentioned above, the utility of the high-skilled is unaffected and that of the low-skilled decreases. If instead $e^{s}<1$, the level of utility of both high- and low-skilled workers will decline. ${ }^{11}$

Table 1: CLR policies: short-run effects

\begin{tabular}{ccc}
\hline \hline & Transition & Steady state \\
\hline Low inequality & $U^{s} \downarrow$ & $U^{s} \downarrow$ \\
$\left(e^{s}<1\right)$ & $U^{u} \uparrow$ & $U^{u} \downarrow$ \\
\hline High inequality & $U^{s}$ constant & $U^{s}$ constant \\
$\left(e^{s}=1\right)$ & $U^{u} \downarrow$ & $U^{u} \downarrow$ \\
\hline \hline
\end{tabular}

The effects of the reduction in child labour productivity $-\theta \downarrow-$ on the utilities of highand low-skilled workers, $U^{s}$ and $U^{u}$ respectively.

\footnotetext{
${ }^{11}$ The proof is equivalent to that of Proposition 5.2.
} 
Table 1 summarises the effects of the CLR policies on the welfare of the two groups. Note, that in the transition, if the degree of inequality is low $\left(e^{s}<1\right)$, CLR policies may improve the welfare of low-skilled workers, while that of high-skilled workers is damaged and therefore a possible conflict of interest can arise.

\subsection{CLR policies: long-run effects}

CLR policies have different effects on inequality in the long run according to whether the economy is in the transition or in the steady state.

Transition Path. Let us assume that high-skilled parents choose the maximum level of education, $e^{s}=1$, while $0 \leq e^{u}<1$. Given these decisions in period $t$, we know the supply of labour in the two markets and the equilibrium wages in period $t+1$. In particular, if no child labour policy is implemented, the number of low-skilled adults from equation (9) is

$$
N_{t+1}^{u}=n_{t}^{u} N_{t}^{u}=\max \left\{\frac{1-\alpha}{z-\theta}, \frac{(1-\alpha)(1-\beta)}{z-\theta(1+b)}\right\} N_{t}^{u} .
$$

On the other hand, the number of high-skilled adults is

$$
N_{t+1}^{s}=n_{t}^{s} N_{t}^{s}=\frac{1-\alpha}{z} N_{t}^{s} .
$$

If, in $t+1, w^{s} h^{u}<w^{u}$, the supply of labour is again $L_{t+1}=\alpha N_{t+1}^{u}$ and $H_{t+1}=\alpha h^{s} N_{t+1}^{s}$, then the ratio $s_{t+1} \equiv H_{t+1} / L_{t+1}$ is

$$
s_{t+1}=\min \left\{\frac{z-\theta}{z}, \frac{z-\theta(1+b)}{z(1-\beta)}\right\} \frac{h^{s} N_{t}^{s}}{N_{t}^{u}} .
$$

It is clear that $s_{t+1}<s_{t}$, hence $w_{t+1}^{u}<w_{t}^{u}$ and $w_{t+1}^{s}>w_{t}^{s}$. This is another way of showing the long-run dynamics of the system as discussed in Section 4 .

The introduction of CLR policies in period $t$ affects the level of wages in $t+1$ and the level of inequality. Let ${ }^{\wedge}$ be the variables at period $t+1$ if a policy against child labour is implemented. First, any reduction in $\theta$ 
generates an increase in the unskilled wage, that is $\hat{w}_{t+1}^{u}>w_{t+1}^{u}$, even if such a reduction in child productivity is insufficient to induce a positive investment in education, that is if $\hat{\theta} \geq \frac{\beta z}{(\beta+b)}$, and $\hat{w}_{t+1}^{s}<w_{t+1}^{s} \cdot{ }^{12}$ Comparing the emergence of the steady state in these two cases, we can conclude that the equilibrium will be the same, but the transition will be slower. Indeed, without any change in $h^{u}$ the equilibrium condition $w^{u}=h^{u} w^{s}$ does not change, but will be reached slowly, i.e. for a $\hat{\tilde{t}}>\tilde{t}$.

If instead $\frac{\beta z}{(1+b)}<\hat{\theta} \leq \frac{\beta z}{(\beta+b)}$, then $\hat{e}^{u}>e^{u}$. As before, the policy tends to slow the divergence in the earnings ratio, inducing a lower dynamic reduction in the wage of the unskilled and a lower dynamic increase in the wage of the skilled. It is easy to verify that the greater the reduction in $\theta$ the higher the wage of the unskilled will be in period $t+1$. The increase in the level of education means that, in period $t+1, \hat{h}_{t+1}^{u}>h_{t+1}^{u}$. Thus, by comparing the long-run dynamics of the introduction of such a policy, the steady state $w^{u}=\hat{h}^{u} w^{s}$ will be reached for a higher wage for the unskilled and a lower wage for the skilled. This means that in the long run, even at a low investment in education, a CLR may have a significant effect on the level of inequality and poverty.

Finally, if $\hat{\theta} \leq \frac{\beta z}{(1+b)}$, the low-skilled stop sending their children to work. Thus, in the next period inequality in the economy disappears. However, given the result of the analysis of the short run, it is very difficult for a government to bring about such a change abruptly, since the welfare of the first generation will be strongly reduced.

When $e^{s}<1$, the result of a CLR policy in the long run is not very different from when $e^{s}=1$. The reduction in $\theta$ leads to an increase in highskilled education and a reduction in fertility. In period $t+1$, such changes tend to increase the income of high-skilled parents. Thus the dynamics may converge to $w^{u}=\hat{h}^{u} w^{s}$ faster than without any CLR policy. However, in the steady state, inequality and poverty decrease.

\footnotetext{
${ }^{12}$ The proof is simple. Consider equation (31), if $\theta$ decreases, $\hat{s}_{t+1}>s_{t+1}$. From equation (2), since $w^{u}$ is an increasing function of $s$ then it increases.
} 
Steady state. A reduction in $\theta$ implies that the thresholds $\frac{\theta(\beta+b)}{\beta z}$ and $\frac{\theta(1+b)}{\beta z}$ shift to the left and the function $r_{t+1}^{s}$ either increases or decreases. When $e^{s}=1$ and $0 \leq e^{u}<1$, a reduction of $\theta$ leads to a decrease of $r_{t+1}^{s}$. As long as $\theta$ decreases, low-skilled parents increase the level of education of their children. Since $h_{t+1}^{s}$ is constant the increase in $h_{t+1}^{u}$ leads to a reduction of $r_{t+1}^{s}$. The impact of a reduction of $\theta$ on $r_{t+1}^{s}$ can be strong enough to induce high-skilled parents to reduce the level of education, i.e. $r_{t+1}^{s}<\theta(1+b) / \beta z$. In particular, if the accumulation of human capital is sufficiently concave $\beta<1 / 2$ - the effect of $h^{u}$ may more than compensate for the direct effect of the change in $\theta$. More precisely, as shown in Appendix C.2, when $\beta<1 / 2$, there is a value of $\theta, \hat{\theta}$ such that if $\theta<\hat{\theta}$ in the new steady state $e^{s}<1$.

The economic intuition behind this result is that, in the new steady state, $w^{s}$ declines and $w^{u}$ increases, thus, parents may choose to send their children partially to work because the income coming from child labour increases relatively to that of high-skilled labour.

When $e^{s}<1$ and $0 \leq e^{u}<1$ the impact of a reduction of $\theta$ on the earnings ratio depends on the initial level of $e^{u}$. If $e^{u}$ is initially greater than zero, any reduction in $\theta$ brings about a decline in $r_{t+1}^{s}$. This is due to the fact that given the concavity in the accumulation of human capital, when $e^{s}<1$, the effect of the CLR policy on the choice of education is stronger for low-skilled agents than for high-skilled ones. Thus the ratio $h^{s} / h^{u}$ in period $t+1$ is lower when the policy is in place than when it is not (for a formal proof of this result see Appendix D). By contrast, when $e^{u}$ is initially equal to zero, the earnings ratio shifts up or down depending on parameters.

\subsection{Alternative policies}

The discussion above holds for any policy that brings about a decline in child labour productivity. However, there are many other methods which may be used to combat child labour.

Mandatory education is a possible instrument. Let us suppose that the government introduces a minimum level of education $\bar{e}$. The optimization 
problem of agent $i$ is to maximize equation (4) under the budget constraint (6) and the inequality $e_{t}^{i}>\bar{e}$ (see Appendix $\mathrm{F}$ for the formal derivation). The mandatory education policy affects household's decisions only if the minimum level of education $\bar{e}$ is greater than the level of education chosen by parents without any such policy being in place.

Assuming that mandatory education does not affect the high-skilled agent's decision (i.e. $e^{s}>\bar{e}$ ), in the transition path equation (20) holds. ${ }^{13}$ Thus, in the short-run, skilled and unskilled wages do not change. The welfare implications are the same as the ones stated in Proposition 5.2. The utility of high-skilled households is unchanged, while the utility of low-skilled households decreases due to the loss of income from children. The same results hold if the economy is in the steady state. The long run implications are equivalent to the case of a reduction in $\theta$ when $\frac{\beta z}{1+b}<\hat{\theta}<\frac{\beta z}{\beta+b}$. Hence, the level of inequality between the two groups will be lower in the steady state.

Another possible policy is a lump-sum increase in the household's whole income (Cigno and Rosati, 2005). Let us assume an increase in the income of low-skilled workers by a certain amount $M$. The budget constraint can be written as follows

$$
c_{t}^{u} \leq\left(1-z n_{t}^{u}\right) I_{t}^{u}+\left(1-e_{t}^{u}\right) \theta w_{t}^{u} n_{t}^{u}+M
$$

The maximization of the utility under (32) does not affect the choice in the level of education, since the opportunity cost of education is unchanged, whereas consumption and the number of children increase due to the income effect. Hence, low-skilled households are better-off, but child labour increases. ${ }^{14}$ On the contrary, a cash transfer conditional to school attendance would avoid this undesirable effect. This transfer is not necessarily an amount of money, but can also be monthly food - such as the Food-forEducation programme in Bangladesh. Defining $d$ the amount of the transfer

\footnotetext{
${ }^{13}$ On the other hand, if $e^{s}<\bar{e}$, the wage ratio would change in favour of low-skilled workers and the results would be comparable to the ones stated in Proposition 5.1.

${ }^{14}$ Behrman and Knowles (1999); Nielsen (1998), among others have found that unconditional cash transfer programmes only affect child labour and school enrolment marginally.
} 
for a unit of education, the opportunity cost of schooling becomes $\theta w_{t}^{u}-d$ (see e.g. Ravallion and Wodon, 2000), and therefore the budget constraint is

$$
c_{t}^{u} \leq\left(1-z n_{t}^{u}\right) I_{t}^{u}+\left(1-e_{t}^{u}\right) \theta w_{t}^{u} n_{t}^{u}+d e_{t}^{u} n_{t}^{u} .
$$

A lower education cost brings about a higher level of education and the choice of the low-skilled agents would depend on the unskilled wage. Hence, the impact of this policy may deeply affect the short-run equilibrium.

\section{Final Remarks}

Historical evidence shows that the introduction of child labour regulation policies in now developed countries has been problematic because of opposition from different groups, in some cases from the industrialists, in others from the working classes. In the same way, in many developing countries, even though they may be obliged through international political pressure to regulate child labour, nevertheless child labour continues to be widespread. This is because there is often insufficient political support to regulate child labour by certain groups.

Our paper highlights how the role of inequality can be crucial in shaping the political support of various income groups (in particular, low- or highskilled workers) for child labour regulation policies. We provide an insight into which groups can be expected to support or to oppose CLR policies by examining the welfare effects of such regulations. In particular, depending on the initial level of inequality, CLR policies affect the welfare of low- and high-skilled households in different ways, thus potentially leading to various conflicts of interests between the two groups. Such frictions may explain the presence of large variations in the incidence of child labour across countries with similar income levels.

Our model also foresees that once CLR policies are in place, the support in favour of these laws by the low-skilled may increase, even if in the shortrun their welfare declines. This is due to the fact that in the long run they will see an increase in their income. 
On the other hand, if the policy is implemented once the economy is in the steady state, the level of human capital of the high-skilled may even decrease, leading to enforcement problems in the long run as well.

An interesting extension of this paper would be to provide an empirical analysis of the link between inequality and political support for child labour regulation. However, this is far from straightforward, since both political support for CLR policies and/or their respective enforcement are difficult to measure and compare across countries. Given this difficulty, a thorough empirical investigation is left to future research.

\section{Appendices}

\section{A Fertility Differential and Transition}

In this Appendix, we show that $r_{t}^{s}$ is always an increasing function of $x_{t}$. In order to simplify the notation we denote: $A=2 \theta \alpha \mu, B=\theta(1-\alpha \mu), C=z \alpha \mu, D=4 \theta(1-\alpha) z \alpha \mu$. Given this simplification we can rewrite equation (22) as follows

$$
r_{t}^{s *}= \begin{cases}\frac{A x_{t}}{B+C x_{t}-\sqrt{\left(C x_{t}-B\right)^{2}+D x_{t}}} & \text { if } x_{1} \leq x_{t} \leq x_{2} \\ \frac{A(1+b) x_{t}}{B(1+b)+C x_{t}-\sqrt{\left[C x_{t}-B(1+b)\right]^{2}+D(1-\beta) x_{t}}} & \text { if } x_{2} \leq x_{t} \leq x_{3} \\ \frac{\mu x_{t}}{1-\mu} & \text { if } x_{3} \leq x_{t} \leq x_{4}\end{cases}
$$

Thus the derivative of the first line in equation (34) w.r.t. $x_{t}$ is positive if

$$
2 B \sqrt{\left(C x_{t}-B\right)^{2}+D x_{t}}>2 B\left(C x_{t}-B\right)-D x_{t} .
$$

By simplifying equation (35), we get

$$
\alpha(1-\mu)>0,
$$

which always holds. The derivative of the second line in equation (34) w.r.t. $x_{t}$ is positive if

$$
2 B(1+b) \sqrt{\left(C x_{t}-B(1+b)\right)^{2}+D(1-\beta) x_{t}}>2 B(1+b)\left(C x_{t}-B(1+b)\right)-D(1-\beta) x_{t} .
$$

By simplifying equation (37), we get

$$
b(1-\alpha \mu)+\alpha(1-\mu)+\beta(1-\alpha)>0,
$$

which always holds. Finally, it is straightforward to verify that the derivative of the third line in equation (34) w.r.t. $x_{t}$ is always positive. Hence, $r_{t}^{s}$ is always an increasing function of $x_{t}$. 


\section{B Corner regimes}

Let $\phi$ be the fraction of low-skilled adults that work as unskilled and $1-\phi$ the fraction of low-skilled adults that work as skilled. Thus, at any period, the equilibrium conditions in the two labour markets require

$$
\begin{gathered}
L_{t}=\left(1-z n_{t}^{u}\right) \phi_{t} N_{t}^{u}+\theta\left[\left(1-e_{t}^{u}\right) n_{t}^{u} N_{t}^{u}+\left(1-e_{t}^{s}\right) n_{t}^{s} N_{t}^{s}\right], \\
H_{t}=\left(1-z n_{t}^{s}\right) h_{t}^{s} N_{t}^{s}+\left(1-z n_{t}^{u}\right)\left(1-\phi_{t}\right) h_{t}^{u} N_{t}^{u} .
\end{gathered}
$$

From equations (39) and (40), there will be only one value of $\phi$ which satisfies equation (23), that is:

$$
\phi_{t}^{*}=\frac{(1-\mu)\left[\left(1-z n_{t}^{u}\right) x_{t} h_{t}^{u}+\left(1-z n_{t}^{s}\right) h_{t}^{s}\right]-\mu h_{t}^{u} \theta\left[\left(1-e_{t}^{u}\right) n_{t}^{u} x_{t}+\left(1-e_{t}^{s}\right) n_{t}^{s}\right]}{\left(1-z n_{t}^{u}\right) x_{t} h_{t}^{u}} .
$$

\section{Long run Dynamics}

We show under which conditions the educational choice of the high-skilled group converges to the equilibrium $H^{L}$ or $H^{S}$ in the two different cases $e^{u}=0$ and $0<e^{u}<1$.

\section{C.1 Case $e^{u}=0$}

When $e_{t}^{u}=0$ - i.e. $\left.\frac{z}{\theta} \leq \frac{(\beta+b)}{\beta}\right)$ - the dynamic of $r_{t+1}^{s}$ is given by

$$
r_{t+1}^{s}=\left\{\begin{array}{cll}
1 & \text { if } & 1 \leq r_{t}^{s} \leq \frac{\theta(\beta+b)}{\beta z}, \\
{\left[\frac{r_{t}^{s} \beta z-\theta \beta(1+b)}{\theta(1-\beta) b}\right]^{\beta}} & \text { if } & \frac{\theta(\beta+b)}{\beta z} \leq r_{t}^{s} \leq \frac{\theta(1+b)}{\beta z}, \\
\left(\frac{1+b}{b}\right)^{\beta} & \text { if } & r_{t}^{s} \geq \frac{\theta(1+b)}{\beta z} .
\end{array}\right.
$$

Note, from Figure 2(a), that the economy converges to the equilibrium $H^{S}$ if, for $r_{t}^{s}=$ $\frac{\theta(1+b)}{\beta z}$,

$$
r_{t+1}^{s}=\left(\frac{1+b}{b}\right)^{\beta} \geq \frac{\theta(1+b)}{\beta z}
$$

that is if

$$
\frac{z}{\theta} \geq\left(\frac{b}{1+b}\right)^{\beta} \frac{(1+b)}{\beta} .
$$

Since, when $e^{u}=0, \frac{z}{\theta} \leq \frac{\beta+b}{\beta}$, the condition (44) can be satisfied only if

$$
\left(\frac{1+b}{b}\right)^{\beta}>\frac{1+b}{\beta+b}
$$

The LHS of equation (45) is increasing in $\beta$, it takes the value 1 if $\beta=0$ and the value $\left(\frac{1+b}{b}\right)$ if $\beta=1$. The RHS is decreasing in $\beta$, it takes the value 1 if $\beta=0$ and the value 
$\left(\frac{1+b}{b}\right)$ if $\beta=1$. Thus, there is a value of $\beta, \tilde{\beta} \in(0,1)$ such that if $\beta>\tilde{\beta}$, the economy converges to $H^{S}$ if inequality (44) holds, while, if $\beta<\tilde{\beta}$ the economy converges to the equilibrium $H^{L}$ for any value of $\frac{z}{\theta}$.

\section{C.2 Case $e^{u}>0$}

When $e_{t}^{u}=\frac{\beta z-\theta(\beta+b)}{\theta(1-\beta)}>0$,

$$
r_{t+1}^{s}=\left\{\begin{array}{lll}
{\left[\frac{r_{t}^{s} z-\theta(1+b)}{z-\theta(1+b)}\right]^{\beta}} & \text { if } & 1 \leq r_{t}^{s} \leq \frac{\theta(1+b)}{\beta z}, \\
{\left[\frac{(1+b)(1-\beta) \theta}{\beta z-\beta \theta(1+b)}\right]^{\beta}} & \text { if } & r_{t}^{s} \geq \frac{\theta(1+b)}{\beta z}
\end{array}\right.
$$

First, let us consider Figure 2(b). Note that the economy converges to the equilibrium $H^{S}$ if, for $r_{t}^{S}=\frac{\theta(1+b)}{\beta z}$,

$$
r_{t+1}^{s}=\left[\frac{(1+b)(1-\beta) \theta}{\beta z-\theta \beta(1+b)}\right]^{\beta}>\frac{\theta(1+b)}{\beta z} .
$$

Let us define $\xi \equiv \frac{z}{\theta}$. It is useful to rewrite inequality (47) as

$$
\left[\frac{\beta(\xi-1-b)}{(1+b)(1-\beta)}\right]^{\beta}<\frac{\xi \beta}{(1+b)},
$$

where the LHS is an increasing concave function in $\xi$, and the RHS is an increasing line. Given that $e^{u}>0$, the relevant interval of $\xi$ is $\frac{\beta+b}{\beta}<\xi<\frac{1+b}{\beta}$. Moreover, both the sides of inequality (48) assume value 1 at $\xi=\frac{1+b}{\beta}$. Thus, if the derivative of the LHS is greater than the derivative of the RHS w.r.t. $\xi$, in $\xi=\frac{1+b}{\beta}$, inequality (48) is always satisfied for any value of $\xi$ and the economy converges to equilibrium $H^{S}$ in Figure 2(b). That is

$$
\left.\frac{\partial\left[\frac{\beta(\xi-1-b)}{(1+b)(1-\beta)}\right]^{\beta}}{\partial \xi}\right|_{\xi=\frac{1+b}{\beta}}=\frac{\beta^{2}}{(1+b)(1-\beta)}>\frac{\beta}{1+b} .
$$

Hence if $\beta>\frac{1}{2}$ then (47) holds for any $\frac{\beta+b}{\beta}<\xi<\frac{1+b}{\beta}$.

If, on the contrary, the LHS of inequality (48) is greater than the RHS for $\xi=\frac{\beta+b}{\beta}$, then the economy converges to the equilibrium $H^{L}$ for any value of $\xi$ in the relevant interval. This happens when

$$
\left(\frac{1+b}{b}\right)^{\beta}<\frac{1+b}{\beta+b}
$$

Since the LHS and the RHS are the same as inequality (45), there is a value of $\beta=\tilde{\beta} \in$ $(0,1)$ such that for every $\beta \leq \tilde{\beta}$ inequality (50) holds. Thus if $\beta \leq \tilde{\beta}$ for any value of $\xi$ the economy converges to the equilibrium $H^{L}$.

In the case in which $\tilde{\beta}<\beta<\frac{1}{2}$, we find that there exists a threshold of $\xi$, i.e. $\zeta \in\left(\frac{\beta+b}{\beta}, \frac{1+b}{\beta}\right)$, such that inequality (48) holds if, and only if, $\xi<\zeta$. Since $\xi \equiv \frac{z}{\theta}$, given $z$ there is a level of $\theta$, that we called $\hat{\theta}$ in the main text, such that inequality (48) holds. 
Finally, we may consider the case in which the function $r_{t+1}^{s}$ is always below the $45^{\circ}$ line. This happens if

$$
\left.\frac{\partial r_{t+1}^{s}}{\partial r_{t}^{s}}\right|_{r_{t}^{s}=1} \leq 1
$$

We have that

$$
\left.\frac{\partial r_{t+1}^{s}}{\partial r_{t}^{s}}\right|_{r_{t}^{s}=1}=\frac{\beta \xi}{\xi-(1+b)} \leq 1
$$

Thus (51) holds if

$$
\xi \geq \frac{1+b}{1-\beta}
$$

It is possible that $\xi=\frac{1+b}{(1-\beta)}$ is not in the relevant interval $\left(\frac{\beta+b}{\beta}, \frac{1+b}{\beta}\right)$. We find that if $\beta \geq 1 / 2, \frac{1+b}{1-\beta} \geq \frac{1+b}{\beta}$, thus $\frac{\partial r_{t+1}^{s}}{\partial r_{t}^{s}}>1$ for every $\xi \in\left(\frac{\beta+b}{\beta}, \frac{1+b}{\beta}\right)$. On the other hand, if $\beta=\hat{\beta} \leq\left(b^{2}+b\right)^{1 / 2}-b<1 / 2, \frac{1+b}{1-\beta} \leq \frac{\beta+b}{\beta}$, thus $\frac{\partial r_{t+1}^{s}}{\partial r_{t}^{s}} \leq 1$ for every $\xi \in\left(\frac{\beta+b}{\beta}, \frac{1+b}{\beta}\right)$.

When $\beta \in(\hat{\beta}, 1 / 2), \frac{\partial r_{t+1}^{s}}{\partial r_{t}^{s}} \leq 1$ if, and only if, $\xi \in\left[\frac{1+b}{1-\beta}, \frac{1+b}{\beta}\right)$.

\section{Effects of CLR policies on the earnings ra- tio}

Let us consider the economy in the steady state with $e^{u}>0$. It is straightforward to note that if $e_{t}^{s}=1$, in period $t+1, r^{s}$ must decline since $h^{u}$ increases and $h^{s}$ is constant. This result holds even if $0<e^{u}<e^{s}<1$. Indeed, from the first row of equation (46) we get

$$
\frac{\partial r_{t+1}^{s}}{\partial \theta}=\left(\frac{z r_{t}^{s}-\theta(1+b)}{z-\theta(1+b)}\right)^{\beta-1} \frac{z \beta^{2}(1+b)}{(1-\beta)^{2} \theta^{2}}\left(r_{t}^{s}-1\right)>0,
$$

since $r_{t}^{s}>1$.

\section{E Effects of CLR policies on the short run}

In this Appendix we prove that if $e^{s}<1$ then any policy inducing a reduction in $\theta$ diminishes the level of utility of high-skilled agents.

Let us consider an economy in the short-run equilibrium characterized by $x_{2} \leq x_{t} \leq x_{3}$. Given equations (9) and (22),

$$
n^{s *}=\frac{(1-\alpha)(1-\beta) 2 \alpha \mu x_{t}}{z \alpha \mu x_{t}-\theta(1+b)(1-\alpha \mu)+\sqrt{\Delta_{2}\left(x_{t}\right)}} .
$$

In this case $\frac{\partial n^{s *}}{\partial \theta} \geq 0$. Indeed

$$
\frac{\partial n^{s *}}{\partial \theta}=\frac{2 \alpha \mu x(1-\alpha)(1-\beta)\left[(1+b)(1-\alpha \mu)-\frac{1}{2} \Delta_{2}^{-\frac{1}{2}} \frac{\partial \Delta_{2}(x)}{\partial \theta}\right]}{\left[\alpha \mu z x-\theta(1+b)(1-\alpha)+\sqrt{\Delta_{2}}\right]^{2}},
$$


where

$$
\Delta_{2}=[z \alpha \mu x-\theta(1+b)(1-\alpha \mu)]^{2}+4 \theta(1+b)(1-\beta)(1-\alpha) z \alpha \mu x .
$$

In order to simplify the notation we define $A=z \alpha \mu x, B=(1+b)(1-\alpha \mu)$ and $C=(1+b)(1-\beta)(1-\alpha)$. Thus we can rewrite $\Delta_{2}$ as follows:

$$
\Delta_{2}=(A-\theta B)^{2}+4 \theta C A,
$$

from which:

$$
\frac{\partial \Delta_{2}}{\partial \theta}=-2 B(A-\theta B)+4 C A,
$$

Thus $\frac{\partial n^{s *}}{\partial \theta} \geq 0$ if:

$$
B\left[(A-\theta B)^{2}+4 \theta C A\right]^{1 / 2}>-B(A-\theta B)+2 C A
$$

which may be simplified as follows:

$$
A(B-C)>0,
$$

by substituting for $\mathrm{B}$ and $\mathrm{A}$ and simplifying yields:

$$
\mu<\frac{1-(1-\alpha)(1-\beta)}{\alpha} .
$$

which always holds since the right hand side is always greater than 1 . Thus $\frac{\partial n^{s *}}{\partial \theta}>0$.

Using $\frac{\partial n^{s *}}{\partial \theta}>0$ we can show that $\frac{\partial \theta w^{u}}{\partial \theta}>0$. From equation (9) we know that if $e^{s}<1$ for a high-skilled workers:

$$
n^{s}=\frac{(1-\alpha)(1-\beta)}{z-(1+b) \frac{\theta w^{u}}{w^{s} h^{s}}} .
$$

since $\frac{\partial w^{s}}{\partial \theta}>0$ then $\frac{\partial n^{s *}}{\partial \theta}>0$ if and only if $\frac{\partial \theta w^{u}}{\partial \theta}>0$.

\section{F Mandatory Education}

With the introduction of a minimum level of mandatory education the optimization of agents is:

$$
\left\{c_{t}, e_{t}, n_{t}\right\}=\operatorname{argmax}\left[\alpha \ln c_{t}^{i}+(1-\alpha) \ln \left(n_{t}^{i} h_{t+1}^{i}\right)\right],
$$

subject to:

$$
c_{t}^{i} \leq\left(1-z n_{t}^{i}\right) I_{t}^{i}+\left(1-e_{t}^{i}\right) \theta w_{t}^{u} n_{t}^{i} .
$$

and

$$
e_{t}^{i} \geq \bar{e}
$$

The Lagrangian is given by

$$
L=\alpha \ln \left[\left(1-z n_{t}^{i}\right) I_{t}^{i}+\left(1-e_{t}^{i}\right) \theta w_{t}^{u} n_{t}^{i}\right]+(1-\alpha) \ln \left[n_{t}^{i} a\left(b+e_{t}^{i}\right)^{\beta}\right]+\mu\left(e_{t}^{i}-\bar{e}\right)
$$

Thus two different cases can arise: 
- if $e_{t}=\bar{e}$ and

$$
n_{t}^{i}=\frac{(1-\alpha) I_{t}^{i}}{z I_{t}^{i}-(1-\bar{e}) \theta w^{u}}
$$

- if $e_{t}>\bar{e}$

$$
e_{t}^{i}= \begin{cases}\frac{\beta z I_{t}^{i}-\theta(\beta+b) w^{u}}{\theta(1-\beta) w^{u}} & \text { if } \frac{\bar{e} \theta(1-\beta) w^{u}+\theta(\beta+b) w^{u}}{\beta z}<I^{i}<\frac{\theta w^{u}(1+b)}{\beta z} \\ 1 & \text { if } I^{i}>\frac{\theta w^{u}(1+b)}{\beta z}\end{cases}
$$

and

$$
n_{t}^{i}= \begin{cases}\frac{(1-\alpha)(1-\beta) I^{i}}{z I^{i}-\theta(1+b) w^{u}} & \text { if } \\ \frac{1-\alpha}{z} & \end{cases}
$$




\section{References}

Azariadis, C. and A. Drazen (1990). Threshold Externalities in Economic Development. The Quarterly Journal of Economics 105(2), 501-526.

Baland, J. and J. Robinson (2000). Is child labor inefficient? Journal of Political Economy 108(4), 663-679.

Balothra, S. (2004). Early childhood investments in human capital: Parental resources and preferences. Bristol Economics Discussion Papers Department of Economics, University of Bristol, UK.

Banerjee, A. (2004). Educational policy and the economics of the family. Journal of Development Economics 74 (1), 3-32.

Basu, K. (1999). Child labor: Cause, consequence, and cure, with remarks on international labor standards. Journal of Economic Literature 37(3), 1083-1119.

Basu, K. (2000). The intriguing relation between adult minimum wage and child labour. Economic Journal 110, 50-31.

Basu, K. and Z. Tzannatos (2003). The Global Child Labor Problem: What Do We Know And What Can We Do? The World Bank Economic Review $17(2), 147-173$.

Basu, K. and P. Van (1998). The economics of child labor. American Economic Review 88(3), 412-427.

Behrman, J. and J. Knowles (1999). Household income and child schooling in vietnam. World Bank Economic Review 13(2).

Cigno, A. and F. Rosati (2005). The Economics of Child Labour. Oxford: Oxford University Press. 
Cunningham, H. (1996). Combating child labor: The british experience. In: Cunningham H., Viazzo P. P. (eds.) Child labour in historical perspective, 1800-1985: case studies from Europe, Japan and Colombia Florence: UNICEF ICDC, pp. 41?55.

Das, S., A. Mourmouras, and P. C. Rangazas (2015). Economic Growth and Development: A Dynamic Dual Economy Approach. Switzerland: Springer International Publishing.

De Herdt, R. (1996). Child labour in belgium: 1800-1914. In: Cunningham H., Viazzo P. P. (eds.) Child labour in historical perspective, 1800-1985: case studies from Europe, Japan and Colombia Florence: UNICEF ICDC, pp. 35-3\%.

De la Croix, D. and M. Doepke (2003). Inequality and Growth: Why Differential Fertility Matters. American Economic Review 93(4), 1091-1113.

De la Croix, D. and M. Doepke (2004). Public versus Private education when differential fertility matters. Journal of Development Economics 73(2), $607-629$.

Dessy, S. E. (2000). A defense of compulsive measures against child labor. Journal of Development Economics 62, 261-275.

Dessy, S. E. and J. Knowles (2008). Why is child labor illegal? European Economic Review 52(7), 1275-311.

Dessy, S. E. and S. Pallage (2001). Child labor and coordination failures. Journal of Development Economics 65 (2), 469-476.

Dessy, S. E. and S. Pallage (2005). A Theory of the worst form of child labour. The Economic Journal 115, 68-87.

Dessy, S. E. and D. Vencatachellum (2003). Explaining cross-country differences in policy response to child labour. Canadian Journal of Economics 36(1), 1-20. 
Doepke, M. and D. Krueger (2006). Origins and Consequences of Child Labor Restrictions: A Macroeconomic Perspective. NBER Working Papers 12665.

Doepke, M. and F. Zilibotti (2005). The Macroeconomics of Child Labour Regulation. American Economic Review 95(5), 1492-1524.

Edmonds, E. V. (2008). Child Labour. In: Schultz T. P. and Strauss J. (eds.) Handbook of Development Economics, Vol. 4, Elsevier Science, Amsterdam, 3607-3710.

Galor, O. and D. Tsiddon (1997). The Distribution of Human Capital and Economic Growth. Journal of Economic Growth 2(1), 93-124.

Galor, O. and D. N. Weil (2000). Population ,Technology, and Growth: from Malthusian Stagnation to the Demographic Transition and Beyond. American Economic Review 90(4), 806-828.

Galor, O. and J. Zeira (1993). Income Distribution and Macroeconomics. Review of Economics Studies 60(1), 35-52.

Hazan, M. and B. Berdugo (2002). Child Labour, Fertility, and Economic Growth. The Economic Journal 112(482), 810-828.

Kleinberg, S. (2005). Children's and Mothers Wage Labor in Three Eastern U.S. Cities, 1880-1920. Social Science History 29(1), 45-76.

Krueger, D. and J. Donohue (2005). On the Distributional Consequences of Child Labor Legislation. International Economic Review 46(3), 785-815.

Moav, O. (2005). Cheap Children and the Persistence of Poverty. The Economic Journal 115, 88-110.

Nardinelli, C. (1990). Child labor and the Industrial Revolution. Bloomington: Indiana University Press. 
Nielsen, H. (1998). Child labour and school attendance: Two joint decisions. Working Paper, Center for Labour Market and Social Research and the University of Aarhus School of Business (98-15).

Ranjan, P. (1999). An economic analysis of child labor. Economics Letters $64(1), 99-105$.

Ranjan, P. (2001). Credit constraints and the phenomenon of child labor. Journal of Development Economics 64, 81-102.

Ravallion, M. and Q. Wodon (2000). Does child labour displace schooling? evidence on behavioural responses to an enrollment subsidy. Economic Journal 110(462).

Stokey, N. L. (1996). Free Trade, Factor Returns, and Factor Accumulation. Journal of Economic Growth 1, 421-447.

Strulik, H. (2004). Economic growth and stagnation with endogenous health and fertility. Journal of Population Economics 17, 433-453.

Weiner, M. (1991). The Child and the State in India. Princeton, NJ: Princeton University Press. 